\title{
AC 2009-823: PATHWAY PROGRAMS FOR UNDERREPRESENTED ETHNIC STUDENTS FROM PRECOLLEGE TO THE COLLEGE OF ENGINEERING
}

\section{Anant Kukreti, University of Cincinnati}

ANANT R. KUKRETI, Ph.D., is an Associate Dean for Engineering Education Research and Professor of Civil and Environmental Engineering at the University of Cincinnati (UC),

Cincinnati Ohio, USA. He joined UC on 8/15/00 and before that worked 22 years at University of Oklahoma. He teaches structural engineering, with research in experimental and finite element analysis of structures. He has won five major university teaching awards, two Professorships, two national ASEE teaching awards, and is internationally recognized in his primary research field.

\section{Kenneth Simonson, University of Cincinnati}

KENNETH SIMONSON joined University of Cincinnati, Cincinnati Ohio, USA as the Assistant Director of the Emerging Ethnic Engineering (E3) Program in 1989, was promoted to the Director's position in 1996, and to Director of Academics in 2001.

\section{Latiera Evans, University of Cincinnati}

LATIERA BRUNSON EVANS is a Post Doctoral Fellow and Research Associate in the Evaluation Services center, College of Education, Criminal Justice, and Human Services, University of Cincinnati, Cincinnati Ohio, USA. 


\section{Pathway Programs For Underrepresented Ethnic Students from Pre-College to the College of Engineering}

\section{Introduction}

With support from the Ohio Board of Regents the Emerging Ethnic Engineers (E3) Program in the College of Engineering at University of Cincinnati (UC), Ohio, U.S.A. has established a series of Pathway Programs leading to their enrollment and graduation from the College of Engineering. The objective of the "Pathway Programs" is to increase the awareness and interest of underrepresented ethnic students in pursuing engineering as an academic major; and to assist in their math/science academic preparation. Underrepresented ethnic students are defined as students whose enrollment numbers have been traditionally low in the college; they consist of African American, Hispanic/Latino, and Native American. Each program has specific objectives, with the long-range goal of increasing the pool of prospective ethnic engineering students from the greater Cincinnati and Northern Kentucky area eligible for admission to the College of Engineering. The Cincinnati Public Schools has the largest concentration of prospective ethnic students; and therefore is the target district, but all of the programs are open to Greater Cincinnati students.

The support received from the Ohio Board of Regents has been used to specifically establish three Pathway Programs beginning with our Family Science Academy (4 $4^{\text {th }}$ to $7^{\text {th }}$ grades), to the Summer Institute ( $8^{\text {th }}$ to $12^{\text {th }}$ grades), and the underrepresented ethnic students accepted into the UC's College of Engineering are invited to participate in our Summer Bridge Program. The E3 Program has a long history of providing pre-college programs; beginning with the Family Science Academy serving 502 students from 1995 -2005, the Summer Institute, serving 316 students form 1990 - 1998, and the Summer Bridge Program for entering underrepresented first year engineering students serving 382 students form 1989 - 2008. Both the Family Science Academy and the Summer Institute were reconstituted in 2007 with emphasis on project-based ;earning activities and contextual learning. While these programs have a long history, an independent evaluation was necessary for all programs to better measure their impact of increasing awareness and interest underrepresented ethnic students; and increasing the success of those students once admitted to the College of Engineering. Beginning in 2007, a independent evaluation process for these programs was implemented and conducted by the UC Evaluation Services Center (UCESC). This paper, first, describes the salient features of the three Pathway Programs and how each was executed during the summer of 2007, second, the paper describes the evaluation plan to conduct the formative and summative assessments of the three programs established by the UCESC, third the evaluation results obtained for the 2007 pathway programs, and, fourth, in conclusion the enhancements planned from the lessons learned. Hopefully, the material presented in this paper will help others plan similar programs at their institutions.

\section{Need for the Programs}

In the past years, there has been an increased discussion on the national and state level regarding the number of students entering science, technology, engineering, and mathematics (STEM) disciplines in general and underrepresented ethnic students in particular. Concerns about these situations and the overall quality of STEM education have been raised in a number of reports, 
notably, those of the National Science Foundation or NSF (Shaping the Future ${ }^{1}$ ), the National Research Council or NRC (Transforming Undergraduate Education ${ }^{2}$ and Improving Undergraduate Instruction in STEM ${ }^{3}$ ), the National Academy of Sciences or NAS (Rising Above the Gathering Storm ${ }^{4}$ ), and the Ohio Board of Regent's Science and Mathematics Education Policy Advisory Council (SAMEPAC) Report ${ }^{5}$. In a world of rapid change, knowledge explosion, and globalization, there is great concern regarding U.S. competitiveness ${ }^{6-9}$. In the 2006 State of The Union Address, former President Bush announced the American Competitiveness Initiative, stressing education as the foundation of a knowledge-based, innovation-driven economy. However, gaps in race/ethnicity and gender at entry and in completion of STEM programs indicate the U.S. struggle to develop a diverse workforce that can compete globally. While intervention programs help narrow these gaps, improvements have been incremental. Some studies have shown that underrepresented (i.e., all women and ethnic men) students drop out of STEM programs at much higher rates. Thus, providing equal access to higher education is necessary but not sufficient to ensure academic success. Colleges and universities must also provide equal opportunity for retention, graduation, and advancement ${ }^{10,11}$.

An area of concern is the academic achievement of K-12 ethnic students. Despite the narrowing of achievement levels between white and ethnic students in the 1980s, especially in math, recent data suggest that the gap may no longer be closing ${ }^{12,13}$. Social scientists attribute this to high poverty levels in ethnic families and lower educational levels among parents. Schools have difficulty compensating for such disadvantages, but extraordinary schools and teachers make a difference in how all students perform. Research in early intervention and one-on-one tutoring demonstrates that at-risk students can achieve higher levels than before ${ }^{14,15}$. There is also evidence that taking challenging STEM courses fosters higher performance ${ }^{16,17}$. Raising student achievement requires teachers to meet not only academic but also social and cultural student needs ${ }^{18}$. This is important as more U.S. public school students are Hispanic (17\%) and African American $(17 \%)$ than teachers $(5 \% \text { and } 8 \% \text {, respectively })^{19}$.

According to 2006, ACT data ${ }^{20}, 163$ underrepresented ethnic students earned at 24/36 on the math component of the test. A 24 is the minimum score Ohio Colleges of Engineering use for admissions. Considering only the above 163 students could be considered for admission to the 13 Ohio engineering college, and assuming that these students applied for engineering, with equal distribution, this results in 13 applicants per college. This is important at the University of Cincinnati $(U C)$ because $96.4 \%$ of college of engineering students is from Ohio.

\section{Goals of the Pathway Programs}

To overcome some of the problems identified above, the College of Engineering through the E3 Program is used as a vehicle to encourage underrepresented ethnic students to participate in the Pathways Programs. The goal is to develop a seamless "pathway" that prepares pre-college students for science, technology, engineering, and mathematics (STEM) careers. These E3 programs seek to create interest, provide exposure, and develop the academic skills necessary for students to pursue an engineering career. In addition, all pathway programs require parent participation. Our proposed E3 Pathway Programs are in line with the "best practices" described in the National Association of Multicultural Engineering Program Advocates (NAMEPA) Region 
C Model Program Workbook ${ }^{21}$ and NACME's Academic Gamesmanship: Becoming a "Master Engineering Student" ${ }^{, 2}$.

The students recruited into the UC's College of Engineering through the aforementioned E3 Pathway Programs are invited to participate in our existing Retention Program beginning with the Summer Bridge Program and a new program, Pathway to Graduate School Program, until they graduate. The overall goal of the retention program is to increase and retain to completion the number of underrepresented ethnic students in the disciplines of Engineering in the UC College of Engineering, and to create the best environment for studying and performing research so that they become well prepared for graduate education and the rigors of the ever-changing global market. Details of these retention and graduate school programs will be subject of another paper.

\section{Family Science Academy}

The Family Science Academy is a Saturday program that meets from 9:00 a.m. to 11:30 a.m. for six weeks. For the summer of 2007 the program enrollment consisted of 65 students and 52 parents (some parents had more than one child participating). The objective of the Family Science Academy is to increase STEM awareness among Cincinnati Public School students but is open to students from Greater Cincinnati area. For six summer weeks at the Academy, children carry out hands-on physics and chemistry experiments in college labs. Meanwhile, their parents are required to attend workshops; the objective of the parents' sessions is to give parents an overview of the importance of math/science and academic preparation necessary for their students to pursue a STEM major. There are sessions also organized is which the parent-student team jointly worked on projects. Details of the student activities, parent workshops, and joint parentstudent activities executed in the 2007 summer are presented next.

\section{$\underline{\text { Orientation Session }}$}

All parents and students were required to attend an orientation program held on the first day. The orientation covered a history of the Family Science Academy, program overview, expectations, and teacher introductions. After the orientation we went into the first parent workshop session, and the students went to the lab to do their first activity planned for the day..

\section{$\underline{\text { Student Activities }}$}

The students were divided into two age specific groups of $4^{\text {th }}$ to $5^{\text {th }}$ grades and $6^{\text {th }}$ to $7^{\text {th }}$ grades. Each group was taught by a separate instructor in laboratories provided by the Chemistry Department. Both groups worked on the same set of science themes, but the activity was designed to match the grade level of the students. There were at total of three activities covering four Saturdays. One of the activities, the deducing density activity, was a two week project that involved teaching the concept of density, and a mini density experiment in week one. In week two, the students implemented the actual experiment. On the fifth Saturday the parents and students participated in a joint robotics activity. The sixth Saturday involved the parent and student team competition. All of the curriculum and experiments were designed to get students to make connections with examples from their daily lives. 
Following three activities were executed for $4^{\text {th }}$ to $5^{\text {th }}$ grades students:

1. Simple Machine Activity. The purpose of this activity was to illustrate how machines work. For this group the students had pictures of machines that they cut out and then identified which group the machines belong to by matching the names of the machines with the pictures. Each student created a poster identifying the machine, explaining what the machine does, and why that job was important. They had to write a short statement about how it relates to life today.

2. Candy Chromatography. The goal of this project is to use paper chromatography to see which dyes are used in the coatings of your favorite colored candies. The students were given a set of materials to design a candy chromatography (pieces of M\&M's, Skittles, Reese's Pieces, food color, filter paper, plastic cup, blow dryer, and toothpicks.). The objective of the activity was teach the students the process of developing a hypothesis, making predictions on the outcomes, and testing to see if the hypothesis was correct. For this group, the instructors assisted the students in learning how to develop the hypothesis. The students put candy pieces on a coffee filter, added water to see if the colors of the candy would dissolve. They charted the results to see which candy colors appeared on the filter after adding water.

3. Deducing Density. The objective was to compare the characteristics of simple physical and chemical changes. The students were given a ball of clay and they dropped the ball of clay in a calibrated jar of water and recorded the change in level of water (see Figure 1). They used this data to calculate the density of the clay. They took the same ball of clay and constructed a boat to see how weight distribution affected density.

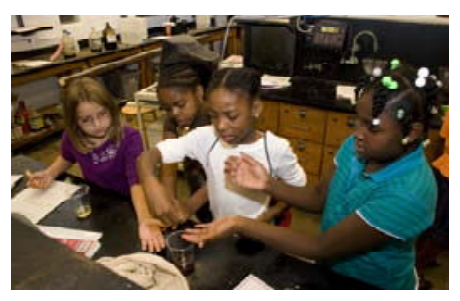

Figure 1. Students Working With Clay Material

Following three activities were executed for the grade $6^{\text {th }}$ to $7^{\text {th }}$ grades students:

1. Simple Machine Activity. For this group, the student were required to examine a group of machines in the lab (pencil sharper, door stop, pulleys, etc.) and answer the following questions; function of the machine, the number of moving parts, how the moving parts were connected to each other, and what parts were elements of the machines. The students made presentations on the comparison of the machines by observing their similarities and differences.

2. Candy Chromatography. The objective for this group was to illustrate how to design a experiment and test their hypothesis. They were given the same set of materials as the younger group, but they were responsible for designing their own experiment based on the chromatography. They had to write how their experiment related to chemistry, explain their hypothesis, what difficulties did they encounter, and what did they learn from the experiment.

3. Deducing Density. The objective for this group of students was to relate the uses, properties and chemical processes to the behavior and or arrangement of small particles that compose matter. The students received a ball of clay and were instructed to test what happens when it was dropped in shoebox of water. The students had to measure the water displaced, and had to answer the question: what would happen if they altered the form of the clay. 


\section{Parent Workshops}

After the orientation on the first day the parents went into the first parent workshop session, which consisted of a presentation on the "Crisis and Need for Students in the STEM Educational Pipeline” By Dr. Anant Kukreti, Associate Dean for Engineering Education Research, UC College of Engineering. This presentation covered the current challenges in STEM Education in the U.S. considering the global job market our students will face upon graduation and the importance of a strong mathematics and science background to meet these challenges. Also, possible solutions to meet these challenges were presented. A question and answer session was held. We found that most parents were unaware of the issues, the importance of them taking ownership of their children's education, and the role they can play and the impact they can have.

Dr. Jeff Johnson conducted the second parent workshop session concentrating on College Science Readiness and How Science Integrates with Engineering Careers. Dr. Johnson is one of the African American Professors in the UC College of Engineering. He obtained his BS degree in engineering from UC and participated in the E3 programs after which he went out to pursue his graduate degrees. The goals of this workshop was to help parents: (1) understand the role and impact of engineering on modern society, and (2) have a better understanding of engineering as a potential career for their children and be able to explain to them the background education and skills necessary for it. The first part is designed to show the contributions of engineering to society, how engineers view and think about the world, what is the $21^{\text {st }}$ century "big challenges," and the process and tools engineers use in discovery, research, and bringing these ideas to use in the real-world. The multi-disciplinary and collaborative nature of engineering is stressed. The second part is designed to help parents better understanding of the work involved in the different fields of engineering, the high school preparation needed to pursue engineering education, what a typical undergraduate engineering curriculum looks like, and the role of graduate education in today's global world workforce. Dr. Johnson also reflected on his undergraduate experiences in the E3 programs and the strategies for success in college. He stressed collaborative learning and the need for the students to take ownership of their education.

In the third parent workshop session, Dr. Kimya Moyo, a Mathematics instructor from Woodward Career Technical High School, discussed the importance of math readiness and how parents could assist their students with understanding Mathematics. She discussed how math and science are integrated in the real world, and the importance in learning both. Dr. Moyo engaged the parents in a hands-on math activity to illustrate how parents could use math with their students to enhance their interest in it.

The presentation for the fourth parent workshop session was given Dr. Joy Moore, Assistant Professor of mathematics, who has been rated as one of the best teachers in math and is an African American with an engineering undergraduate degree. Dr. Moore graduated with a BS in engineering degree and then pursued graduate degrees in mathematics education. Dr. Moore stressed the importance of parent's role in developing student's attitudes and behavior necessary for academic success. She narrated her life experiences and the role played by her parents in molding her career. 


\section{$\underline{\text { Joint Parent-Student Team Activity }}$}

To cultivate interaction between parents and children that is focused on science activities, following two activities were conducted in which the parent and student participated as a team:

1. Robotics Project. _Ms. Linda Neenan and staff from Cincinnati iSpace Organization was the presenter for this session. Ms. Neenan and her staff provided Lego robotics for the students and parents to program. The students worked with iSpace staff member Jane Doe to learn how to program a robot to run on the track. The students and parents assembled in the auditorium, where each student had a chance to demonstrate how the robot worked. They learned how to put together a robot and program it via an infrared signal from a laptop computer using RIS or RoboLab software to perform desired movements/functions. The parents assisted the children in completing their projects. The iSpace Organization also discussed with the parents how they can set up a Robotics Club in their school district and the financial assistance and professional help available to enter into the First Robotics Competition.

2. Terrific Tower Competition. This competition was coordinated on the last day of the program by the doctoral Fellows participating in the NSF Graduate K-12 Fellows STEP (Science and Technology Expansion Project) grant in which the students and their parents were given a set of materials to be used to design and build a tower that need to be a minimum of 5 or more inches tall with a platform to hold a paper cup. Thus this project served as the capstone experience. A fixed time limit for designing and constructing was specified. The objective was to see which tower could hold the most pennies. Figure 2 shows a Fellow testing one of the towers. The judging parameters used by the STEP Fellows were: correct height of the tower, total number of pennies the tower could hold on a cup, and which cup held

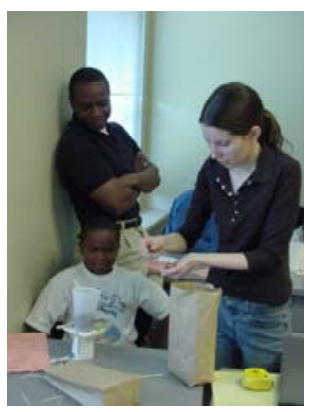

Figure 2. STEP Fellow Testing a Tower the most pennies. If more than one tower held the same amount of pennies, then the tiebreaker was the tallest structure. Students were awarded first, second, and third prizes for the Terrific Tower competition. At the end of the competition, certificates were awarded to parents and students. Students with perfect attendance received a trophy.

\section{Summer Institute}

The Summer Institute is offered to students who have earned a "B" average or higher in math and science courses during the academic year. The five-week program met Monday to Thursday, 9:00 a.m. - 3:30 p.m., and Fridays were reserved for hands-on activities organized by engineering faculty members and for field trips. The objective of Summer Institute is also to deepen the awareness and interest of underrepresented ethnic students in STEM, targeting Cincinnati Public Schools, but open to students from greater Cincinnati. Our goal is to assist in the development of students' math/science preparation and understanding of these disciplines as they relate to engineering. The Institute seeks to improve student's understanding of science and math through hands-on classroom and lab experiences. These activities emphasize: Content, the "what" of science and math; Attitude, the idea that subjects can be mastered; and Process, the method of using science and math as a tool to resolve everyday problems. In summer of 2007 Summer Institute 16 students participated. The institute was structured so that each group participated in a structured 90 minute lesson session followed by a 60 minute related hands-on or computer 
applications laboratory experience in science and math. In the computer lab, students concentrated on researching information associated primarily with their science assignments. The students were divided into two groups (explained below). From Monday to Thursday, Group I attended science session in the morning and math session in the afternoon, and Group II did the vice-versa. The students took a mathematics pre-test to gauge their prior proficiency and this information was used to divide them into two groups based on the demonstrated abilities and skill level.

Group I students were instructed in a more basic math curriculum consisting of reference sheets (outlining student's responsibilities, study techniques, key definitions/properties, symbols and common words/phrases used in word problems; Tech Prep Application Sheets, and excerpts from Success in Algebra and Basic Mathematics for Trades and Technologies) with each lesson plan. Each lesson plan included a skill check exercise to monitor each student's progress. Their first week curriculum consisted of defining/using absolute value, defining complementary angles, solving linear equations, and inequalities. Students also learned how to translate algebraic expressions. In the second week, the course material related to: solving rational equations/portions, ratios, and modeling equations. The Head of the UC Department of Electrical and Computer Engineering, Dr. Hal Carter, provided a demonstration on how long a battery could provide power if it was used to power a light bulb or LED (a semiconductor diode that converts applied voltage to light and is used in digital displays, as of a calculator). The third week gave students the opportunity to go over the equations and inequalities part of the pre-test and give demonstrations of inequality problems. There were demonstrations by faculty members from UC Departments of Aerospace Engineering and Biomedical Engineering. In the fourth week, students corrected their packets on algebraic manipulation, performed basic operations on algebraic terms, and solved simple step equations. The fifth week included calculating the mean, median, and mode of a data set, solving linear equations by graphing, and solving systems using multiplication.

Group II was the more advanced group, some of the areas covered were: algebraic and geometric tests for symmetry with respect to the origin, and $\mathrm{x}$ and $\mathrm{y}$ axes; solving quadratic equations using the quadratic formula; factoring; graphing; finding trigonometric values for exact quadrant angles; and solving linear inequalities. An assignment was given for each area, homework was checked once a week, and students were given an opportunity to re-work incorrect problems. In week one, students classified sets of numbers, used interval notation, solved linear inequalities, and computed compound interest. In the second week the students were required to recognize special factoring patterns, solve quadratic equations by factoring, review expectations of syllabus; discuss factoring techniques, articulation of algorithms, and model expressions and equations. The third week consisted of students determining symmetry using algebraic tests, determining the domain and range of a given relation/function, and classifying functions with graphs. In the fourth week, the students discussed how to follow instructions without prompting, converting degrees to radians and vice versa, using basic definitions of trigonometric ratios, and calculating exact trigonometric values for angles in radian form. There were presentations by the faculty members from UC Departments of Chemical and Materials Engineering and Mechanical Engineering. In the final and fifth week, students finished the curriculum by learning how to determine reference angles for angles, and finding exact trigonometry values using the unit circle. 
The Science Component of the institute consisted of six academic content standards in the following order: Earth Science, Life Science, Physical Science, Science and Technology, Scientific Inquiry, and Scientific Ways of Thinking. The three areas of instruction used to assist students in putting the curriculum into context were Science Vocabulary, How to Write Up Experiments, Power Point presentations, and to create a scientific brochure on Biomes. Each lesson plan included objectives, materials, procedures, and assessment. In the first week, students learned the "scientific method" and science vocabulary with the objective of getting them to understand how to sort and classify raw information by creating bar graphs. The second week consisted of learning how to make inferences, writing a description and taking notes (journal) on the information collected. For example, students were asked to observe a picture of a before and after storm and make inferences based on prior knowledge. The third week allowed students to present information busing some of skills taught in previous weeks in the form of a brochure on Biomes. Students were required to choose a Biome, create a travel brochure, and give a presentation on the brochure. Some examples of the Biomes

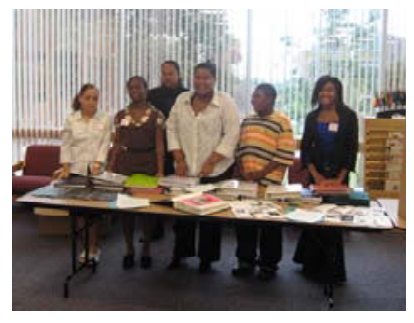

Figure 2. Students Display Work brochure were: the Amazon Rainforest, Tropical Rainforest of South America, and the Deciduous Forests of the United States. Figure 3 shows the students displaying their work to the parents who were invited for the event. During the fourth week, students learned how to develop a PowerPoint presentation. The objective was to work in small groups, learn to research and develop their ideas. The students had specific roles, such as facilitator, time-keeper, recorder, researchers, and supplies manager. The fifth week of the program consisted of learning the basic components of an experiment and how to write a research paper.

\section{Summer Bridge Program}

Overview. The E3 Summer Bridge Program (offered for the $19^{\text {th }}$ year) is a seven-week residential program for incoming under-represented ethnic engineering freshman. The objective of the program is to create a "learning community" of E3 students who develop the academic and social skills necessary for achieving academic excellence from the freshman year through graduation. This process begins with the students taking the following courses during the program, PreCalculus, Calculus, Chemistry, Physics, and English. During the program, bridge students enroll as a 'learning community' cohort for their fall quarter courses that include cooperative learning classes in calculus and physics. The cooperative learning course extends to the sophomore year for physics and differential equations. In each subsequent quarter of the freshman year, they continue to register as a learning community cohort. This process is part of the E3 Retention Program (not discussed in this paper) that seeks to increase the academic performance and graduation rates of underrepresented ethnic students.

Residential Arrangement. Summer Bridge participants are housed in campus facilities by gender and supervised by our Resident Manager, Mr. James Copeland, a teacher at Hughes High School and a member of the staff for thirteen years. He is the liaison with the resident hall administration and staff. Mr. Copeland organizes all social activities and monitors each student's compliance with program rules and regulations. 
Opening Session. The E3 administrative staff, instructors and current E3 students conducted the mandatory orientation session on July 24, 2007. Mr. Kenneth Simonson and Dr. Anant Kukreti highlighted the goals, objectives, and expectations of the program. After the orientation, there was a separate meeting with parents to discuss how they can assist in making sure that their student would be academically successful from Summer Bridge through graduation. A unique part of this meeting was the presentation of the five-year plan that illustrated what their student should be doing as a member of the E3 program from freshman through senior year.

Bridge Classes. All bridge students take a math pre-test to determine whether they would take the calculus or pre-calculus track during the program. Students enter one of two sections and follow their sequence of courses. One of the major objectives of the Summer Bridge coursework is prepare students for their perspective math and science courses taken the freshman year. A critical part of this effort is the implementation of the cooperative learning process in all of the courses, and prepares them for the math and science cooperative learning community courses taken by E3 students' freshman year. Cooperative learning is an instructor methodology that requires students to interact on a higher level than in a traditional classroom setting. It involves learning methods and techniques using cooperative task structures in which students spend time working in 3-6 member heterogeneous groups, as shown in Figure 4. Students are required to work collectively toward the common goal of mastering the course material.

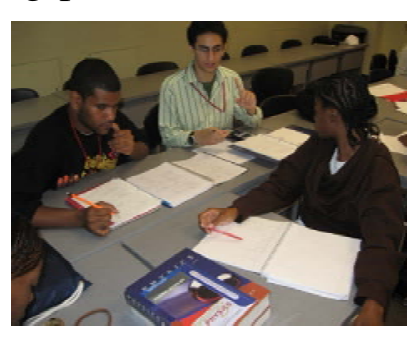

Figure 4. Cooperative Learning Session

Evening Study Sessions. Mandatory study sessions are held from Monday through Friday from 6:00 to 8:00 p.m., and are coordinated by our resident manger. Current E3 students assist in the study sessions by making sure that the bridge students are implementing the collaborative learning process during the study sessions.

Staff Input Sessions. The complete staff meets weekly to discuss the process made by students and to gauge how well they are implementing the collaborative learning process. Figure 5 shows a meeting in progress. The resident manager provides information on their performance in the study sessions and in the residence hall. Each course instructor talks about the performance of the students in their course, and in particular they talk about students who are having difficulty and what they plan to do to address the problem. Instructors compare notes

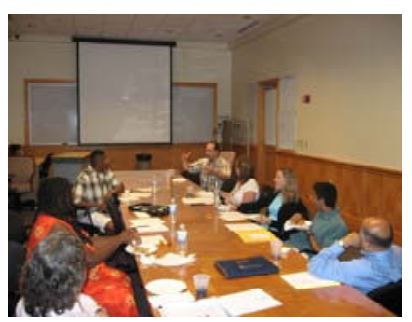

Figure 5. Staff Meeting on students to see if the same students are having difficulty in more than one course, and students who are performing at a higher level

Field Trips. The bridge students visited four area companies that included the following: (1) Procter and Gamble Health Care Headquarters; (2) General Electric Aircraft Engines Jet Engine Training Center; (3) Toyota Motor Engineering and Manufacturing North America, Inc. headquarters in Erlanger, Kentucky; and (4) Toyota's Georgetown, Kentucky manufacturing plant, which produces the Avalon, Camry, Camry Hydrid, and the Solora vehicles. During these visits the students learned background information on the companies, structure of the different divisions, and possible co-op assignments. Most of the field visits are organized by our past E3 
students working in these companies, who talk to the students of their experiences and the scholastic expectations from students to qualify for co-op job opportunities in their companies and others.

Performance Evaluation. During the last week of the program students complete their final exams and attend an exit interview for each course. All students are required to prepare a written assessment of their performance, and they receive a written assessment from each instructor. The objective of the assessments and exit interviews is to give students specific information with regard to their academic and social development. In an effort to have the students use the information from the assessments and exit interviews, all instructors prepared homework for students to complete and turn in on weekly basis up to start of fall quarter.

Closing Ceremony. The closing ceremony was held on the last day and was attended by the Dean of College of Engineering, Provost, Vice Provost for Academic Affairs, and Vice Provost for Diversity. A highlight of the closing was the presentation of the "Nia" and "Most Improved Student" awards, which were voted by a consensus of the instructors. The Nia award is for the student who best represents the objectives of the program; one student is selected from each section of courses. The Most Improved Student Award is given to a student(s) who has made the most progress during the program; one student from each course is selected for the award.

\section{Other K-12 Outreach and College Retention Programs}

In addition to the E3 Program, the UC College of Engineering has formed the Rowe Center for Women in Engineering ( $R C W E$ ), which conducts two main K-12 outreach activities: (1) "Explore Engineering" day for 6-10 graders with hands-on activities and demonstrations, (2) math tutoring for the Women's Connection serving ethnic grade school students; and (3) a week long Summer Camp for 20-30 high school participants focusing on: (a) presentations on goal setting, organizing, study skills, and business etiquette; (b) a dinner with current women engineering students; and (c) dorm housing chaperoned by current women engineering students and RCWE Director, with evening activities to acquaint them with Cincinnati. Targeting ethnic populations also advances RCWE's goals, since generally at most universities women comprise a greater percentage of ethnic engineering students than in the general student body ${ }^{23}$.

The UC College of Engineering annually also conducts the JETS Tests of Engineering Aptitude, Mathematics and Science, which is a unique and challenging academic program enabling teams of high-school students to learn team development and problem-solving skills, and then participate in an open-book, open-discussion, engineering problem competition. The highest scoring Varsity Teams in each enrollment categories receive a \$5000 Tuition Scholarship. The scholarship is awarded to the high school. Then the award is distributed to any participating member on the team who has applied and is accepted into the College of Engineering. Also, each year in February the Department of Civil and Environmental Engineering hosts the Bridge Building Competition which provides high school students an opportunity to learn how engineers use STEM to design real structures - in the context of a hands-on model bridge-building project. In 200731 high schools sent 51 teams for a total of 450 students that participated in the event. 
From a Supplement Grant to a Research Experiences for Teachers (RET) Site from NSF we have developed and implemented a Pre-Engineering course for High Schools. The University of Cincinnati collaborated with four Cincinnati-area high schools to develop and offer a program that introduces students to the practice of Engineering and Engineering Technology. The College of Applied Science and the College of Engineering worked together to provide content that would provide high school students a balanced view of the careers and opportunities available in Engineering and Engineering Technology. Our goal for the course is that greater numbers of students would understand the practice of engineering and engineering technology and would choose to pursue these in their college studies. More information on the program can be found at www.eng.uc.edu/eet. The program is primarily project-based with students working in teams to investigate and solve engineering related problems. Project work is supplemented with instruction on engineering disciplines and topics.

To recruit and retain minorities and women in engineering a special Scholarship Program called S-STEM is funded by NSF to support a total of 32 engineering women and ethnic minority undergraduate scholars. The students started in the program in fall of 2007 and are currently sophomores and our participating in our Programs to Enhance Retention which includes: (1) freshmen and sophomore Supplemental Cooperative Learning classes in Calculus, Physics, and Chemistry to provide a solid foundation to build-on; (2) academic assessment and monitoring program to track academic progress towards degree program; (3) faculty-driven and peer mentoring program, corporate mentoring program, and monthly socials: (4) monthly socials which provide an opportunity to interact with successful professionals from industry and academia; (5) participating in a Corporate Mentoring Program which includes shadowing and opportunity to understand the corporate world and skills needed to succeed in it; (6) participating in a mandatory six-quarter internship and paid cooperative (co-op) education program, which places students in the work-place; and (7) participate in a structured service learning outreach project, preferably a K-12 outreach project, for 10 hours per quarter for quarters in school. Select students are provided an opportunity to participate in a special Pathway to Graduate School Program to guide and motivate talented underrepresented engineering students to prepare for and pursue graduate studies.

The above K-12 outreach programs, the E3 Pathway Programs described in this paper, the Retention and Enrichment Programs implemented for those who join the undergraduate programs in the UC College of Engineering, and the Pathway to Graduate School for those intending to purse graduate studies are integrated together to form the "Ticket-To-Ride" Pathway Program. The sequencing and integration of the elements this program is shown in Figure 6.

\section{Evaluation Plan}

The University of Cincinnati Evaluation Services Center conducts the evaluation of the Pathway Activities Programs. The overall evaluation question for the pathway programs described in this paper is "What is the effectiveness of the pathway created by the E3 programs?" The long term question for the E3 program staff is "Do the pathway programs increase the number of students in Engineering in University of Cincinnati's College of Engineering?" Evaluation questions include: (1) How effective is the research design? How well do the pathway programs address E3 


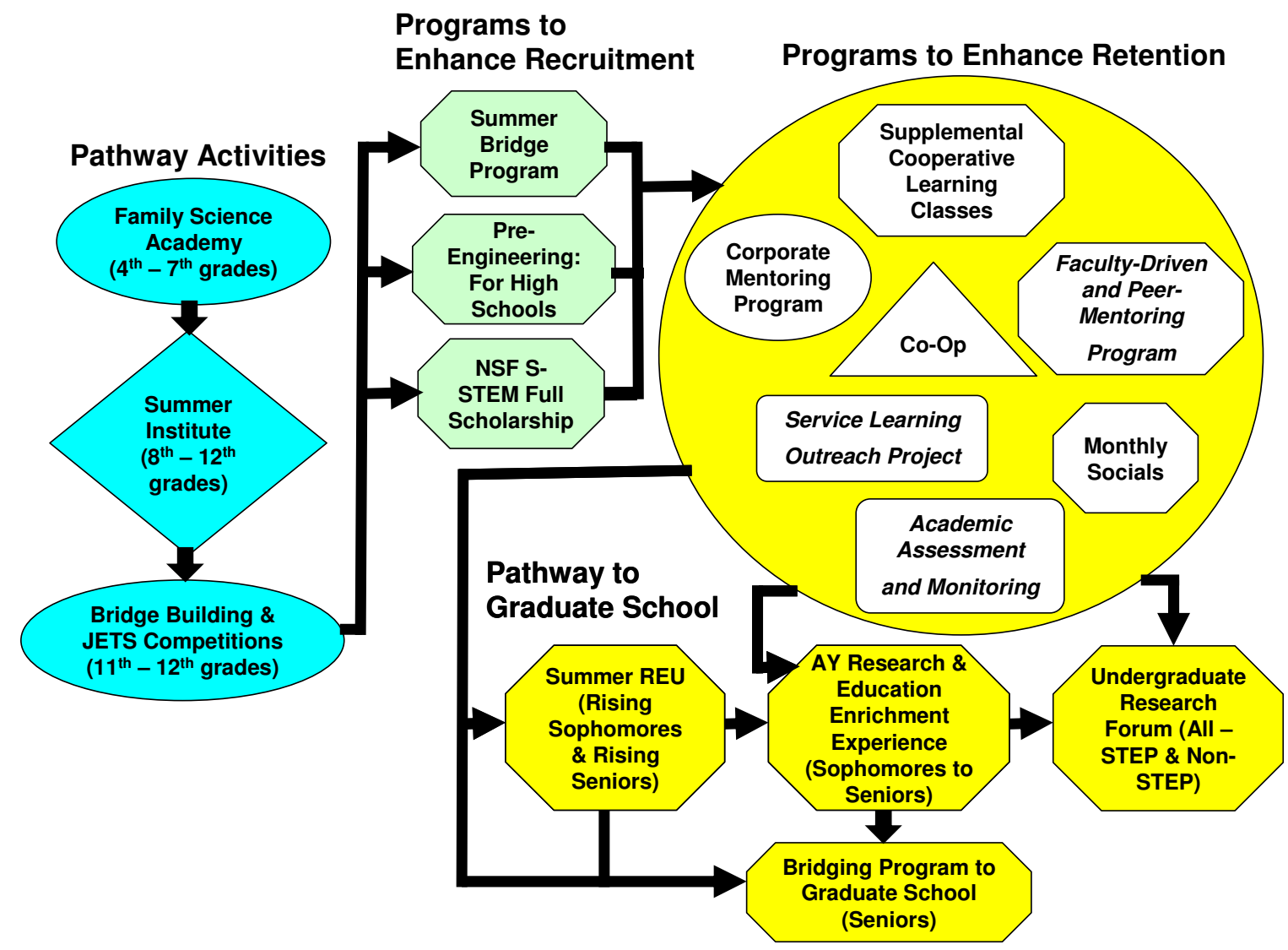

Figure 6. Elements Integrated to From the" Ticket-To-Ride" Pathway Program

program's long term goal? Can the overall pathway program design provide scientific evidence?; and (2) Are conducted pathway programs consistent with the design? What problems have surfaced, and how effective are the solutions? To answer these questions, the evaluator will assess each pathway program individually (formative evaluation) leading to an overall evaluation of progress towards E3 program's long term goal and objectives (summative evaluation). Summative evaluations will be written annually to assess accountability, impact, sustainability, and gauge progress towards E3 program's long term goal and objectives. Evaluation activities will gather direct and indirect data from project stakeholders, K-12 students, parents, college bound students (Bridge students), professionals, instructors, and faculty. Indirect data collection measures will include surveys, and interviews, and direct measures will include enrollment, and grades. To build continuous improvement, the evaluator will give formative evaluations to the E3 program staff regularly to track progress and guide program changes to increase impact. Changes to pathway programs will be documented by the E3 program staff and included in the evaluation. This data collection strategy enables triangulation of findings to strengthen program conclusions. Evaluation activities for each pathway program (details presented below) include gathering student data, learning and research activity evaluations, and interviews or surveys of all project participants.

The evaluation questions and evaluation activities/timeline for the three pathway programs are as follows: 
- Family Science Academy:

- Evaluation Questions:

- How effective was the recruiting process?

- How satisfied were the participants with the orientation and sessions?

- Do participants (students and parents) understand what STEM careers are and the role math and science play within these careers?

- Does the number of students participating in the program meet long term goals?

- Evaluation Activities/Timeline:

- Document recruiting activities

- Obtain recruitment materials

- Survey participants to determine recruitment, program satisfaction, what they learned, and whether or not expectations were met:

- Survey students

- Survey parents

- Survey staff (Instructors)

- Observe sessions to assist in data interpretation

- Analyze data collected and provide necessary reports

- Summer Institute

- Evaluation Questions:

- How effective was the recruiting process?

- How effective was the execution of the Summer Institute?

- How satisfied were the participant with the orientation and sessions?

- How has the students' understanding of science and mathematics changed as a result of participation in the Institute?

- How did attendance in program activities affect academic course choices in mathematics and science?

- Does the number of students participating in the program meet long-term goals?

- Evaluation Activities/Timeline:

- Document recruiting activities:

- Obtain recruitment materials

- Confirmation of demographic information on applications

- Survey students to determine recruitment, program satisfaction, what they learned, and whether or not expectations were met

- Survey staff (Instructors)

- Observe sessions to assist in data interpretation

- Focus groups with participants (students and parents)

- Analyze data collected and provide necessary reports

- Summer Bridge Program:

- Evaluation Questions:

- How effective was the execution of the Summer Bridge Program?

- How did participation impact academic performance of the students during their freshman year?

- How effective was the program in assisting the student's transition from high school to college? 
- Evaluation Activities/Timeline:

- Review agenda and program materials

- Review STEP Fellow session observations to assist in data interpretation

- Review student exit interviews

- Student survey/interviews after Autumn quarter and end of freshmen year

- Orientation

- Academic preparation

- Future plans

- Interview instructors of freshmen courses (Math, Physics and Chemistry) to get their perspective on E3 impacts.

- Analyze data collected and provide necessary reports

\section{Evaluation Results}

Family Science Academy. Fifty-two students and 50 parents completed hard copy surveys on the last day of the Family Science Academy. The students responded that they learned a lot from the program (78\% responded positively), and $73.1 \%$ of them responded that they understood what was being presented in their science lab. The parents responded very positively about the program, they suggested adding an increased number of joint hands-on experiences with their children during the program. The following verbatim comment from a parent reflects the expressed desire of several parents. "I think it should be more time for families to work together. In our society we do so many things away from each other, this would be a good place to work together on projects as a family."

Summer Institute. The Summer Institute evaluation was conducted by two hard copy surveys: one to student participants and one to their parents. The majority of student participants (71\%) reported that they enjoyed the Summer Institute. They also reported that the program increased their interest in science (71\%) and mathematics (59\%). Some of the student comments were: "I liked the new things that I learned in math and science". "The things I like the best about Summer Institute was that it taught me how to be consistent with due dates." "I like being exposed to the college atmosphere (what to expect in college)." Overall parents were positive about the experience their children had in the program. The following comments reflects those of the majority of the parents; "The summer program is an excellent program. It is a snapshot of the college experience. I am grateful that my son was able to participate." Parent's responses were very positive, $68.5 \%$ saw an increase in their student's interest in math and science. When asked what the UC College of Engineering could do to help prepare students for college, both parents and students responded that they could provide more information about STEM careers, college preparation, and financial support.

Summer Bridge Program. The evaluation for the participants of the 2007 E3 Summer Bridge Program consisted of two surveys, one in September 2007 at the conclusion of the summer program and prior to starting their Freshmen year and one in June 2008, at the conclusion of their Freshman year and group discussions at the end of their Freshman year. The second survey administered in June of 2008 evaluated the effect of the Summer Bridge Program and the academic year retention support program that includes cooperative learning courses, monthly socials, academic monitoring through progress reports on the student's first year academic 
preparation and performance. After completing the surveys, the students were randomly assigned to four groups and asked to participate in small group discussions.

Ninety-five percent of the students responded that participation in the Summer Bridge Program had improved their academic performance during their freshman year. All 100\% of the students thought that their participation had given them an advantage over students who had not participated. As a result of classes taken during the Summer Bridge Program, out of the students who responded $91 \%$ felt they were better prepared for Calculus, $87 \%$ in Physics, $78 \%$ in Chemistry, and 35\% in English. Eighty-seven percent of the students thought the cooperative learning courses helped them to succeed during their first year. The additional explanations of lecture topics by the instructors, the help with practice problems, and in-depth individual attention were cited as features they liked best about these classes. The cooperative learning courses are one-hour credit supplemental instructional courses that the students take in parallel to their lecture courses. This process is a continuation of the Summer Bridge Program, where students were placed in cooperative learning groups. The objective is for the students to master the concepts of their Calculus and Physics courses. Our goal is for $100 \%$ the E3 students to earn a C or better in these courses.

An analysis of the academic data for the 2007 Summer Bridge students are as follows: In the 2007 fall quarter 18 students completed Calculus 250 (Pre-Calculus) with 100\% earning a $\mathrm{C}$ or better; 5 students completed Calculus 251 with $100 \%$ earning a $\mathrm{C}$ or better. In the 2008 winter quarter 18 students completed Calculus 251 with $100 \%$ earning a $\mathrm{C}$ or better; 20 students completed Physics 201 with $100 \%$ earning a C or better; three of students (Biomedical) did not take Physics until their sophomore year, and one student withdrew from the course.

In the 2007 fall quarter 56\% of the students earned Deans' List Honors compared to $12 \%$ the College of Engineering first year students. The bridge students earned a cumulative grade point average was 3.05 for the 2007-2008 academic year compared to a 2.86 grade point average for majority engineering students. Ninety-one percent of the 23 bridge students returned to the College of Engineering for their sophomore year, one student transferred to the College of Business, and one student left the University of Cincinnati.

\section{Conclusions}

The first formative evaluation of the Emerging Ethnic Engineers Pathway Programs, Family Science Academy, and the Summer Institute, indicate that the programs met their stated objectives of increasing the awareness and interest of greater Cincinnati underrepresented ethnic students by offering a series of Pathway Programs shown in Figure 6. Longitudinal data will be needed to analyze the effect of the Pathway programs, Family Science Academy and the Summer Institute on the recruitment of underrepresented students to the College of Engineering. The Summer Bridge Program and the academic year retention infrastructure had a significant impact in the preparation and academic performance of first year underrepresented ethnic students.

Based on the evaluation results we plan to implement the following enhancements for the Pathway Programs:

- Family Science Academy: 
1. To increase the number of joint parent and student hands-on activities during the sessions.

2. Create cross-disciplinary teams of faculty from engineering faculty, and the other STEM majors to develop course activities, demonstrations, and lab experiments associated with the program.

- Summer Institute:

1. Implement project based learning as a strategy for increasing the student's understanding of the math and science content by demonstrating their real-world applications.

2. Use pre-test to better align students' abilities for implementing the team projects.

3. Use pre- and post-test measurements to analyze whether course and curriculum objectives are being met.

- Summer Bridge Program:

1. Work with engineering faculty to implement project-based learning as a pilot, with the goal of increasing the bridge student's understanding of math and science concepts and their relationship to engineering.

2. Use pre- and post-test measurements to analyze whether course and curriculum objectives are met.

\section{Acknowledgements}

The authors acknowledge the $\$ 60,000$ support given by the Ohio Board of Regents for the programs.

\section{Bibliography}

1. National Science Foundation. (1996). Shaping the Future: New Expectations for Undergraduate Education in Science, Mathematics, Engineering, and Technology. Report on its review of undergraduate education by the advisory committee to the Directorate for Education and Human Resources, Chairman M.D. George. NSF: Arlington, VA.

2. National Research Council. (1999). Transforming Undergraduate Education in Science, Mathematics, and Engineering. Washington, D.C.: Committee on Undergraduate Science Education, Center for Science, Mathematics, and Engineering Education, National Academy Press.

3. National Research Council. (2003). Improving Undergraduate Instruction in Science, Technology, Engineering, and Mathematics. Editor, DeHaan, R.L. Washington, D.C.: Committee on Undergraduate Science Education.

4. National Academy of Sciences, National Academy of Engineering, Institute of Medicine. (2005). Rising Above The Gathering Storm: Energizing and Employing America for A Brighter Economic Future. Committee on Prospering in the Global Economy of the 21st Century: An Agenda for American Science and Technology. Washington, D.C.: NAS. Available at www.nap.edu.

5. Ohio Science and Mathematics Education Policy Advisory Council. (2006). Science and Mathematics: A Formula for 21st Century Success. Julian M. Earls and Karen A. Holbrook, Co-Chairs, Ohio Board of Regents, $36 \mathrm{pp}$. Available at http://regents.ohio.gov/samepac/reports/SAMEPAC_REPORT_FINAL_1-22.pdf

6. Business-Higher Education Forum. (2002). Investing in People: Developing All of America's Talent on Campus and in the Workplace. Washington, D.C.: American Council on Education.

7. National Science Board. (2004). Science Indicators, 2004, Volume 2, Appendix Table 2-34.

8. Smalley, R.E. (2003). "Nanotechnology, the S\&T Workforce, Energy, and Prosperity," Presentation to the President's Council of Advisors on Science and Technology (PCAST), Rice University, March 3, 2003.

Available at 
http://cohesion.rice.edu/NaturalSciences/Smalley/emplibrary/PCAST\%20March\%203,\%202003.ppt\#432,8,Slide 8.

9. National Science Foundation. (2005). The Engineering Workforce: Current State, Issues, and Recommendations: Final Report to the Assistant Director of Engineering, National Science Foundation. Task Force Members: Charles E. Blue, Linda G. Blevins, Patrick Carriere, Gary Gabriele, Sue Kemnitzer (Group Leader), Vittal Roa, and Galip Ulsoy, May, 2005.

10. Richardson, R., and Skinner, E. (1992). Helping First Generation Ethnic Students Achieve Degrees. In Zwerling, L. and London, H. editors, First-Generation Students: Confronting the Cultural Issues, (New Direction for Community Colleges), 80, Winter. San Francisco: Jossey-Bass.

11. Huang, G., Taddese, N., and Walter, E. (2000). Entry and Persistence of Women and Minorities in College Science and Engineering Education. Washington, D.C.: National Center for Education Statistics, U.S. Department of Education, Office of Educational Research and Improvement.

12. U.S. Department of Education, National Center for Education Statistics. (1995). 1994 NAEP Reading: A First Look. Washington, D.C.: May, NCES 95-748.

13. National Assessment Governing Board. (2003). Statement on NAEP Mathematics and Reading Report Card, Released on November 13, 2003 by John H. Stevens, Member, National Assessment Governing Board. Available at http://www.nagb.org/release/statement_11_03.html.

14. Slavin, R. E., Karweit, N. L., and Wasik, B. A. (1994). "Preventing Early School Failure: What Works," Educational Leadership, December 1992/January 1993, pp. 10-18; idem, Eds. Preventing Early School Failure. Boston: Allyn and Bacon.

15. Wasik, B. A., and Slavin, R. E. (1993). "Preventing Early Reading Failure with One-to- One Tutoring: A Review of Five Programs," Educational Research Quarterly, Vol. 28, pp. 178-200.

16. Rock, D. A., and Pollack, J. M. (1995). Statistics in Brief: Mathematics Course-Taking and Gains in Mathematics Achievement. Washington, D.C.: U.S. Department of Education, National Center for Education Statistics, NCES 95-714.

17. Hoffer, T., Rasinski, K., and Moore, W. (1995). Social Background Differences in High School Mathematics and Science Course taking and Achievement. Washington, D.C.: U.S. Department of Education, National Center for Education Statistics, NCES 95-206.

18. Urban Learner Framework. (2003). Available at http://www.learningbridges.com/Urban.aspx.

19. National Center for Education Statistics. (2004). Digest of Education Statistics 2003. Publication ID: ERN3799P, ED ID: NCES-2005-025, Publication Date: 12/01/04. Available at http://www.ed.gov/about/pubs/intro/index.html?src=gu.

20. ACT Enrollment Information Services Report. (2006). Enrollment Information.

21. Prather, E. (1994). MEP Model. Chicago, IL: National Association of Ethnic Engineering Program Administration - Region C.

22. Landis, R. (1987). Academic Gamesmanship: Becoming a "Master Engineering Student. National Action Council for Ethnic In Engineering.

23. American Society of Engineering Educators (2002). 2001 Profiles of Engineering and Engineering Technology Colleges, ASEE, June. 